\title{
Developmental Ability of CD-1 Strain Mouse Embryos In Vitro and In Vivo with the Different Glucose Phosphate Isomerase Patterns
}

\author{
Yoko KATO ${ }^{1,2)}$, Miho TANIMURA ${ }^{2)}$ and Yukio TSUNODA ${ }^{1,2)}$ \\ 1) Research Institute for Animal Developmental Biotechnology and ${ }^{2)}$ Laboratory of \\ Animal Reproduction, College of Agriculture, Kinki University, Nara 631, Japan
}

\begin{abstract}
Glucose phosphate isomerase (GPI)-1AA and GPI-1BB homozygotes were produced by natural mating of CD-1 strain mice and the several reproductive characteristics of both homozygotes were compared. The pregnancy rate, period required for copulation and litter size were essentially the same. The developmental ability of GPI-1AA zygotes and 2-cell embryos in vitro was significantly lower than that of GPI-1BB (60 vs 75\% and 75 vs $98 \%$, respectively). After preservation at $4 \mathrm{C}$ for $24 \mathrm{~h}$, the proportion of the GPI-1AA-2-cell embryos developed to blastocysts was significantly low (28 vs 57\%). After transfer of GPI-1AA embryos to recipient mice, the developmental potential into fetus was similar or significantly superior to that of GPI-1BB (19 vs $24 \%$ and 47 vs $14 \%$, respectively). When both embryos were aggregated at the $8-16$-cell stage and transferred to recipients, $76 \%$ of the young $(13 / 17)$ was chimeras and both isozymes types were observed in most tissues analyzed. In conclusion, both GPI-1AA and GPI-1BB embryos of the CD-1 strain mice were equally useful for researches in developmental biology and biotechnology, their features being basically the same.
\end{abstract}

Key words: Glucose phosphate isomerase (GPI), In vitro development, Chimera, Aggregation.

(J. Reprod. Dev. 43: 205-211, 1997)

$\mathbf{G}$

lucose phosphate isomerase (GPI) molecules first become evident during oogenesis as oocyte-coded gene products $[1,2]$. They are replaced by embryo coded products between 8-cell to morula stages in the mouse [1]. GPI is a dimer whose electrophoretical pattern is fixed as GPI-1AA or GPI-1BB in inbred strain mice and hybrid heterozygotes produced by mating each pattern mice show three banded patterns, corresponding to enzyme molecules of constitution GPI-1AA, AB and BB [3, 4]. Sensitivity for detecting GPI activity is quite high and thus GPI patterns are commonly used as a marker to examine cell fate in the mouse [5]. Although CD-1 strain mice are widely used for

Accepted for publication: April 26, 1997 experimental manipulation of preimplantation embryos, the GPI pattern is not fixed. A CD-1 strain mouse whose GPI type is temporarily fixed to GPI-1AA [6] or BB [7] has thus been used. However, the question whether GPI-1AA and GPI-1BB preimplantation embryos have the same developmental ability is still unclear.

In this study, we established CD-1 strain mice of fixed GPI type and compared the fertility and developmental ability of preimplantation embryos in vitro and in vivo.

\section{Materials and Methods}

\section{Electrophoresis}

GPI patterns were analyzed according to the pro- 
cedures of Eicher and Washburn [8] and Mikami and Onishi [9]. One volume of red blood cells was mixed with four volumes of distilled water and in the case of homogenized tissue samples, 20 volumes of distilled water. Electrophoresis was conducted on Titan III iso-vis cellulose acetate plates (Helena Laboratories, USA) with phosphate buffered saline $(\mathrm{pH} 6.8)$ at $160 \mathrm{~V}$ for $1 \mathrm{~h}$. The plates impregnated with the staining mixture [8] at $37 \mathrm{C}$ for several minutes and then were washed with distilled water and the Intensity of each GPI activity was measured with a densitometer (Helena Laboratory).

\section{Production of homozygous mice}

GPI-1AA and GPI-1BB mice were previously selected by GPI analysis of red blood cells, and females were mated with the same type of male mice. Homozygous mice were established by brother-sister mating for at least 3 generations. The pregnancy rate, period required for copulation and litter size were recorded. Body weights of 22 GPI$1 \mathrm{AA}$ and 27 GPI-1BB young were measured weekly from the first to the fifth week after birth.

\section{Developmental ability of zygotes and 2-cell embryos in vitro and in vivo}

GPI-1AA and GPI-1BB mice were superovulated with 5 IU pregnant mare serum gonadotropin (PMSG), followed $48 \mathrm{~h}$ later by 5 IU human chorionic gonadotropin (hCG). After mating with males of the same GPI type, zygotes and 2-cell embryos were obtained from the oviducts at $20 \mathrm{~h}$ and $43 \mathrm{~h}$ after hCG injection, respectively. Cumulus cells around zygotes were removed with hyaluronidase (300 units/ml M2 medium) [10] and embryos possessing 2 pronuclei and a second polar body were regarded as zygotes. Ten zygotes were cultured with $10 \mu \mathrm{l}$ M16 medium [11] with $100 \mu \mathrm{M}$ EDTA supplementation [12] for 4 days, while ten 2-cell embryos were cultured with $10 \mu \mathrm{l}$ M16 medium without EDTA for 3 days. The developmental process of embryos was observed every day and embryos that developed into morulae and blastocysts were transferred to uteri of day 3 GPI-1AA or GPI-1BB pseudopregnant female mice. On days 15 to 17 of pregnancy, live fetuses and implantation sites were examined and counted.
Low temperature preservation of 2-cell embryos in vitro

Two-cell embryos obtained as above were preserved at $4 \mathrm{C}$ for 24 to $72 \mathrm{~h}$ in M2 medium supplemented with $20 \%$ fetal calf serum (FCS), and with or without $0.5 \mathrm{M}$ sucrose[13]. After preservation, the embryos were cultured in M16 medium in vitro for 3 days.

\section{Developmental ability of heterozygous 2-cell embryos}

The developmental ability of 2-cell embryos from superovulated GPI-1AA females mated with GPI$1 \mathrm{BB}$ males was compared with that of GPI-1BB females mated with GPI-1AA males. Superovulation, collection of 2-cell stage embryos and in vitro culture system were the same as above.

Production of GPI-1AA $\leftrightarrow$ GPI-1BB chimeric mice

Eight to 16-cell stage homozygous embryos were recovered from GPI-1AA and GPI-1BB mice $68 \mathrm{~h}$ after hCG injection. Zonae pellucidae of the embryos were digested by $0.5 \%$ pronase in PBS for 7 $\mathrm{min}$ at $37 \mathrm{C}$. Zona-free embryos were washed in M2 medium and pairs of embryos, GPI-1AA and GPI-1BB, were aggregated [14] in M2 medium supplemented with phytohemagglutinin $(5 \mu \mathrm{l} / \mathrm{ml})$. The aggregated embryos were cultured in M16 medium and those that developed to single morulae or blastocysts were transferred to pseudopregnant recipients. Females were allowed to go to term. The contribution of each GPI type in red blood cells and tissues from the heart, kidneys, liver, lungs, spleen and gonads of the young were examined. The distribution of germ cells in chimeric animals was assessed by mating chimeras with GPI-1AA mice. When young showed only the GPI$1 \mathrm{AA}$ or GPI-1AB type, all germ cells in chimeras were regarded as GPI-1AA or GPI-1BB, but if both types were observed, the germ cells were considered to be chimeric.

Statistical significance was examined by $\mathrm{t}$ test and $\chi^{2}$ analysis.

\section{Results}

CD-1 strain mice have been bred at random in a closed colony for 6 years following their purchase from Japan Charles River Inc (Atsugi, Japan). GPI- 
1AA homozygotes were superior to GPI-1BB homozygotes in our colony (69 vs $6 \%$ in males and 74 vs $0 \%$ in females) and a few GPI-1AB heterozygotes were observed ( $25 \%$ of males and $26 \%$ of females). GPI-1BB females were produced by mating GPI-1AB mice with each other and approximately one fourth of the young were GPI1BB homozygotes. In both homozygotes obtained after brother-sister mating for at least 3 generations, red blood cells, heart, kidney, liver, lung, spleen, gonads and germ cells showed the same GPI pattern.

\section{Fertility and weight of young}

Table 1 shows the fertility of both types of mice. Pregnancy rate, periods required for copulation, litter size and sex ratio were essentially the same in both strains. The weight of the male mice in both types was greater than that of females at any age (data not shown). Differences in weight for mice of the same sex were not observed although GPI-1AA males were significantly lighter than GPI1BB males at the first week after birth (data not shown).

\section{Developmental ability of early stage embryos in vitro and in vivo}

In vitro culture experiments were repeated for 4 to 5 times. Both types of embryos were collected on the same day and cultured with the same medium. Table 2 shows the developmental ability of zygotes and 2-cell embryos in vitro. Most of zygotes and 2-cell embryos in both types developed to the 4-cell stages, respectively $(87-100 \%)$. However, the proportion of embryos that developed to morulae to blastocysts was significantly higher in GPI-1BB embryos compared with that of GPI$1 \mathrm{AA}(60$ vs $75 \%$ from zygotes and 75 vs $98 \%$ from 2-cell embryos, respectively). Table 3 demonstrates the in vivo development at day 15-17 after transfer of each morulae and blastocysts to recipient uteri. There was no difference among GPI types of recipient females in the pregnancy rate and thus the data are listed together. After transfer of embryos developed from zygotes to recipient mice, the similar proportion of embryos developed to day 15-17 fetuses in both groups (19 vs 24\%). When morulae to blastocysts developed from 2-cell embryos were transferred to recipients, significantly higher proportion of fetuses was obtained from GPI-1AA embryos (47 vs 14\%), however the rate of production of fetuses was very low in all groups (14-47\%) with unclear reason.

Low temperature preservation of 2-cell embryos

Table 4 shows the proportion of blastocysts

Table 1. Fertility of male mice with the different GPI patterns

\begin{tabular}{cccccc}
\hline GPI & $\begin{array}{c}\text { Pregnancy } \\
\text { pattern }\end{array}$ & rate & $\begin{array}{c}\text { Days for copulation } \\
(\text { Mean } \pm \text { SD) }\end{array}$ & $\begin{array}{c}\text { Litter size } \\
(\text { Mean } \pm \text { SD) }\end{array}$ & \multicolumn{2}{c}{ No. of (Mean \pm SD) } \\
\cline { 5 - 6 } AA & $56 / 62(90)$ & $3.7 \pm 2.2$ & $12.3 \pm 2.8$ & $\begin{array}{c}6.0 \pm 2.3 \\
(49)\end{array}$ & $\begin{array}{c}6.3 \pm 2.5 \\
(51)\end{array}$ \\
& & & & $4.9 \pm 2.3$ & $\begin{array}{c}7.3 \pm 2.8 \\
(60)\end{array}$ \\
\hline
\end{tabular}

Table 2. In vitro development of zygotes and 2-cell embryos of each GPI pattern

\begin{tabular}{lccccc}
\hline $\begin{array}{l}\text { Stage of } \\
\text { embryos } \\
\text { cultured }\end{array}$ & GPI pattern & No. & \multicolumn{2}{c}{ No. of embryos developed to(\%) } \\
\cline { 4 - 6 } & & used & 2-cell & 4-cell & morula-blastocyst \\
\hline Zygote & AA & 297 & $297(100)$ & $258(87)$ & $177(60)^{\mathrm{a}}$ \\
& BB & 268 & $268(100)$ & $241(90)$ & $202(75)^{\mathrm{b}}$ \\
2 2-cell & AA & 118 & - & $111(94)$ & $89(75)^{\mathrm{a}}$ \\
& BB & 82 & - & $82(100)$ & $80(98)^{\mathrm{b}}$ \\
\hline
\end{tabular}

$\mathrm{a}-\mathrm{b} \mathrm{p}<0.05$ 
which developed from homozygous 2-cell embryos preserved at $4 \mathrm{C}$ for 24 to $72 \mathrm{~h}$. There was no clear effect of sucrose supplement, so the data was come together. Ninety-five to 134 embryos were subjected to each treatment. After storage for $24 \mathrm{~h}$ in M2 medium with or without sucrose, the developmental rate to blastocysts of GPI-1BB embryos was significantly $(\mathrm{p}<0.05)$ higher than those of GPI$1 \mathrm{AA}$ embryos (57 vs 28\%). After a $48-\mathrm{h}$ preservation, the developmental ability was low (17 vs $5 \%)$.
Developmental ability of heterozygous 2-cell embryos

Experiments were repeated for 3 times. Table 5 shows the developmental ability of heterozygous 2-cell embryos in vitro. The developmental rates of embryos from GPI-1AA females mated with GPI1BB males to 4-cell and 8-cell stages were similar to those of embryos from GPI-1BB females mated with GPI-1AA males (93 vs $85 \%, 78$ vs $85 \%$, respectively). The proportions of embryos from GPI-1AA females mated with GPI-1BB males de-

Table 3. In vivo development of zygotes and 2-cell embryos of each GPI pattern

\begin{tabular}{lcccc}
\hline $\begin{array}{l}\text { Stage of } \\
\text { embryos } \\
\text { cultured }\end{array}$ & $\begin{array}{c}\text { GPI } \\
\text { pattern }\end{array}$ & $\begin{array}{c}\text { No. of embryos } \\
\text { transferred }\end{array}$ & $\begin{array}{r}\text { Pregnants } / \\
\text { Recipients }\end{array}$ & $\begin{array}{c}\text { No. of live } \\
\text { fetuses }\end{array}$ \\
\hline Zygote & AA & 156 & $12 / 19(63)$ & $22(19)$ \\
& BB & 148 & $10 / 20(50)$ & $21(24)$ \\
2-cell & AA & 74 & $9 / 11(82)$ & $28(47)^{\mathrm{a}}$ \\
& BB & 71 & $9 / 14(64)$ & $10(14)^{\mathrm{b}}$ \\
\hline
\end{tabular}

a-b $\mathrm{p}<0.05$.

Table 4. In vitro development of each types of 2-cell embryos preserved at $4 \mathrm{C}$

\begin{tabular}{cccc}
\hline \multirow{2}{*}{$\begin{array}{c}\text { Period for } \\
\text { preservation }\end{array}$} & GPI & \multicolumn{2}{c}{ Number of embryos $(\%)$} \\
\cline { 3 - 4 } & pattern & used & developed to blastocyst \\
\hline \multirow{2}{*}{0} & AA & 119 & $99(83)$ \\
& BB & 95 & $82(86)$ \\
24 & AA & 125 & $35(28)^{\mathrm{a}}$ \\
48 & BB & 122 & $70(57)^{\mathrm{b}}$ \\
72 & AA & 133 & $22(17)^{\mathrm{a}}$ \\
& BB & 101 & $5(5)^{\mathrm{b}}$ \\
& AA & 134 & $2(1)$ \\
& BB & 124 & $1(1)$ \\
\hline
\end{tabular}

$\mathrm{a}-\mathrm{b} \mathrm{p}<0.05$.

Table 5. In vitro development of heterozygous 2-cell embryos in vitro

\begin{tabular}{|c|c|c|c|c|c|c|}
\hline \multicolumn{2}{|c|}{$\begin{array}{c}\text { GPI } \\
\text { Pattern of parents }\end{array}$} & \multirow{2}{*}{$\begin{array}{l}\text { No. of embryos } \\
\text { cultured }\end{array}$} & \multicolumn{4}{|c|}{ No. of embryos developed to $(\%)$} \\
\hline female & male & & 4-cell & 8-cell & morula & blastocyst \\
\hline AA & BB & 40 & $37(93)$ & $31(78)$ & $24(60)^{a}$ & $19(48)^{a}$ \\
\hline BB & AA & 40 & $34(85)$ & $34(85)$ & $33(83)^{b}$ & $31(78)^{\mathrm{b}}$ \\
\hline
\end{tabular}

a-b $\mathrm{p}<0.05$. 
veloped to morulae and blastocysts were significantly lower than those from the reciprocal mating (60 vs $83 \%$ and 48 vs $78 \%$, respectively).

\section{Analysis of GPI-1AA $\leftrightarrow$ GPI-1BB chimeric mice}

Table 6 presents the results of aggregation of GPI-1AA embryos with GPI-1BB embryos in vitro and in vivo. Thirty three of the 40 embryos developed into single morulae or blastocysts and after being transferred to recipients, 17 young were obtained $(52 \%)$. Sex ratio was biased against male $(11 / 17,65 \%)$. Thirteen mice including 8 males showed chimerism in red blood cells $(13 / 17,76 \%)$. The other 4 mice including 3 males showed only a GPI-1AA band (24\%) in all tissues examined.

Table 7 shows the approximate proportions of the densities in GPI-1AA/BB band in various tissues from chimeras. Germ line chimerism was assessed by the mating test. Chimerism was detected in all tissues examined except male No.1 in which the chimerism was observed only in red blood cells. The sperm of male chimeras showed only one type of GPI except mouse No.4. In females, chimerism was frequently observed.

\section{Discussion}

Two homozygous mice with different GPI type, GPI-1AA and GPI-1BB, were produced from the same strain mouse. Although there is no GPI-1BB homozygotes in our laboratory, it is possible to keep the breeding of GPI-1BB homozygotes (data not shown). We examined whether the homozygotes have similar reproductive ability and are useful for the research in developmental biology and biotechnology. The fertility of adult mice and the developmental ability of early stage embryos were thus compared. The GPI pattern in red blood cells, heart, kidneys, liver, lungs, spleen and gonads was first confirmed not to be mutated after at least three generational brother-sister mating of homozygotes. Secondly, the pregnancy rate, required period for copulation, litter size and body weight of young were not affected by the difference in GPI type. Thirdly, the developmental ability of early stage embryos of both types was essentially the same except in vitro experiments. The in vitro developmental ability of GPI-1AA zygotes and 2-

Table 6. Production of GPI-1AA $\Leftrightarrow$ GPI-1BB chimeric mice

\begin{tabular}{|c|c|c|c|c|c|c|}
\hline \multicolumn{2}{|c|}{ No. of embryos } & \multirow{2}{*}{$\begin{array}{c}\text { No. pregnant/ } \\
\text { Transferred }\end{array}$} & \multirow{2}{*}{$\begin{array}{l}\text { No. of } \\
\text { young }\end{array}$} & \multicolumn{3}{|c|}{ GPI patterns of blood } \\
\hline aggregated & transferred & & & AA & $\mathrm{BB}$ & chimera \\
\hline 40 & 33 & $3 / 3(100)$ & $17(52)$ & $4(24)$ & 0 & 13(76) \\
\hline
\end{tabular}

Table 7. Approximate proportions of GPI-1AA homologous type in varied tissues of chimeric mice

\begin{tabular}{rlrrrrrrrr}
\hline \multicolumn{2}{c}{ Chimera } & \multicolumn{7}{c}{ Tissues $(\%)$} \\
\cline { 4 - 8 } No. & Sex & blood & heart & kidney & liver & lung & spleen & gonads & germ cell * $^{*}$ \\
\hline 1 & male & 74 & 100 & 100 & 100 & 100 & 100 & 100 & 100 \\
2 & male & 67 & 80 & 70 & 75 & 85 & 83 & 100 & 100 \\
3 & male & 43 & 42 & 59 & 34 & 44 & 48 & 77 & 100 \\
4 & male & 71 & 71 & 68 & 64 & 75 & 68 & 49 & 11 \\
5 & male & 61 & 53 & 40 & 49 & 49 & 39 & 39 & 0 \\
6 & male & 53 & 61 & 63 & 61 & 66 & 46 & 46 & 0 \\
7 & male & 50 & 57 & 41 & 46 & 55 & 28 & 28 & 0 \\
8 & male & 36 & 38 & 45 & 43 & 45 & 28 & 28 & 0 \\
9 & female & 79 & 78 & 82 & 83 & 84 & 78 & 76 & 100 \\
10 & female & 80 & 83 & 73 & 78 & 85 & 82 & 84 & 62 \\
11 & female & 66 & 55 & 69 & 72 & 61 & 64 & 28 & 69 \\
12 & female & 64 & 67 & 64 & 62 & 68 & 58 & 73 & 38 \\
13 & female & 43 & 50 & 62 & 51 & 56 & 39 & 63 & 60 \\
\hline
\end{tabular}

${ }^{*}$ mating test. 
cell embryos to morula or blastocyst stage was significantly less than in GPI-1BB zygotes and embryos. The developmental ability of GPI-1AA2-cell embryos following low temperature preservation for $24 \mathrm{~h}$ was also less compared to embryos from GPI-1BB mice. Although the reason is not clear, GPI-1AA embryos were more sensitive for the in vitro treatments. The in vitro developmental ability of 2-cell embryos from GPI1AA females mated with GPI-1BB males was significantly lower than that obtained from the reciprocal mating. The weaker developmental ability of GPI-1AA embryos in vitro is thus suggested due to GPI encoded by maternal Gpi-1a.

However, after being transferred to recipient mice, the developmental potential of GPI-1AA embryos into fetuses was similar or higher than those of GPI-1BB embryos (19 vs $24 \%$ and 47 vs $14 \%$ ), but the proportion were extremely low in all groups. Though the reason of the low proportion was unclear, transfer into uteri might be one of the possible reason and transfer into oviducts would be useful [15].

Chimeric mice were obtained by aggregating GPI-1AA and GPI-1BB embryos. In most chimeras, both types of GPI were detected in all tissues. However, GPI type of male germ cells after mating test were extremely partial to one type (3 males were GPI-1AA only, 4 males were GPI-1BB only and only one was mixed). The reason was still unclear in the present study but it was suggested from other works that about two thirds male chimeras consisted of $X X / X Y$ chimera $[14,16]$ and almost all chimeras having mono-progeny was derived from $X X / X Y$ male chimeras [17]. In the present study, though the number of chimeras was limited, the sex ratio that was slightly partial to male $(11 / 17,65 \%)$ suggests that they were $X X / X Y$ males. Although the reason why no GPI-1BB homozygote was obtained is unclear, most GPI-1BB cells might happen to locate outside at compacted morulae after aggregation and they could not contribute to inner cell mass area at the blastocyst stage which form the fetus itself [18].

In conclusion, the homozygous CD-1 strain mouse for Gpi-1 locus has essentially the same fertile ability, because GPI-1AA and GPI-1BB preimplantation embryos had similar developmental ability in vivo, and well-balanced chimeric mice were produced by aggregation method following transfer to recipients. This indicates that both homozygous mice are equally useful for researches in biology and biotechnology.

\section{Acknowledgment}

This study was supported by grants from the Ministry of Education, Science and Culture (No.082522110, 087602265), Special Coordination Funds for Promoting Science and Technology from the Science and Technology Agency, pioneering research project in biotechnology from Ministry of Agriculture, Forestry and Fisheries, the Human Science Foundation and Kinki University (9634).

\section{References}

1. Brinster RL. Parental glucose phosphate isomerase activity in three-day mouse embryos. Biochem Genetics 1973; 9: 187-191.

2. McLaren A, Buehr M. GPI expression in female germ cells of the mouse. Genet Res Comb 1981; 37: 303-309.

3. West JD, Flockhart JH. Genetic differences in glucose phosphate isomerase activity among mouse embryos. Development 1989; 107: 465-472.

4. Petzoldt U. Developmental profile of glucose phosphated isomeraseallozymes in parthenogenetic and tetraploid mouse embryos. Development 1991; 112: 471-476.

5. Gardner RL, Rossant J. Investigation of the fate of $4.5 \mathrm{~d}$ post coitummouse ICM cells by blastocyst injection. J Embryol Exp Morphol 1979; 52: 141-152

6. Kato Y, Tsunoda Y. Pluripotency of mouse embryonic cells on germline at 3.5-8.5 and 11.5 days post-coitum after aggregation with precompacted embryos. Develop Growth Differ 1995 ;37: 79-84.

7. Nagy A, Rossant J, Nagy R, Abramow-Newerly W, Roder JC. Derivation of completely cell culture-derived mice from early-passage embryonic stem cells. Proc Natl Acad Sci 1993; 90: 8424-8428.

8. Eicher EM, Washburn LL. Assignment of genes to regions of mouse chromosomes. Proc Natl Acad Sci 1978; 75: 946-950.

9. Mikami H, Onishi A. 'Heterosis' in litter size of chimeric mice. Genet Res Com 1985; 46: 85-94.

10. Fulton BP, Whittingham DG. Activation of mam- 
malian oocytes by intercellular injection of calcium. Nature 1978; 273: 149-151.

11. Whittingham DG. Culture of mouse ova. J Reprod Fertil 1971; 14: 7-21.

12. Abramczuk J, Solter D, Koprowski H. The beneficial effect of EDTA on development of mouse one-cell embryos in chemically defined medium. Dev Biol 1977; 61: 378-383.

13. Kasai M, Niwa K, Iritani A. Protective effect of sucrose on the survival of mouse and rat embryos stored at 0 C. J Reprod Fertil 1983; 68: 377-380.

14. Tarkowski AK. Mouse chimeras developed from fused eggs. Nature 1961; 190: 857-860.

15. Tsunoda Y, McLaren A. Effect of various proce- dures on the viability of mouse embryos containing half the normal number of blastomeres. $J$ Reprod Fertil 1983; 69: 315-322.

16. Tarkowski AK. Studies on mouse chimeras developed from eggs fused in vitro. Natl Cancer Inst Monograph 1963; 11: 51-71.

17. Ford CE, Evans EP, Burtenshaw MD, Clegg HM, Tuffrey M, Barnes RD. A functional 'sex-reversed' oocyte in the mouse. Proc Roy Soc Lond B190; 187-197.

18. Tarkowski AK, Wroblewska J. Development of blastomeres of mouse eggs isolated at the 4 and 8 cell stage. J Embryol Exp Morphol 1967; 18: 155-180. 